\title{
Conflictos en la representación de la identidad, desde la ausencia
}

\author{
Elizabeth Padilla
}

\section{Cine por la identidad como recurso para la intervención}

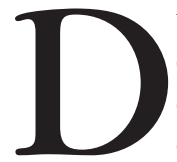
urante el periodo comprendido entre 1976 y 1983 se produjeron en la Argentina violaciones de los derechos humanos y crímenes de lesa humanidad, resultado de la dictadura militar. Una de las categorías perversas que inauguró el denominado proceso militar fue la del "detenido-desaparecido", personas sustraídas de sus hogares, lugares de trabajo, universidades o escuelas y que aún hoy, pasados ya más de treinta años, se desconoce su paradero. A esta categoría se sumó el del secuestro de sus hijos, mucho de ellos nacidos en cautiverio, entregados a represores o a personas afines a la ideología de la dictadura e inscritos como hijos biológicos. Mediante esta forma se sustituyó la filiación original por otra, resultado de la apropiación, con graves consecuencias sobre la identidad de los hijos. Los familiares de las víctimas recurrieron, en sus intervenciones públicas, a creativas formas de expresión con el fin de compaginar el trabajo de la búsqueda con denuncias y demandas de justicia. ${ }^{1}$ Tal es el caso de las acciones llevadas a cabo por las asociaciones de Abuelas y Madres de Plaza de Mayo, y posteriormente por la de Hijos.

Entre las investigaciones que procuraron esclarecer los delitos del "proceso" sobre la sociedad y el individuo, resultan de especial relevancia, por sus consecuencias éticas, las que intentaron responder a cuestiones relativas a la recuperación o restitución de la identidad de los hijos de los desaparecidos, así como el esclarecimiento del paradero de estos últimos. Dichas cuestiones, inéditas en cuanto a su complejidad, fueron indagadas - a pedido de las

${ }^{1}$ Para una versión más detallada de este tema véase Elizabeth Padilla, "El problema de la restitución de las identidades apropiadas”, en Raúl Alcalá Campos y Mónica Gómez Salazar, Construcción de identidades. México, unAM, Facultad de Estudios Superiores Acatlán, 2008. 
principales asociaciones de derechos humanos- por distintos grupos de profesionales, entre ellos juristas, genetistas, psicólogos, antropólogos forenses y filósofos. Esa actividad produjo resultados innovadores que fueron aplicados eficazmente en nuestro país como en el resto del mundo. Las mismas consistieron, principalmente, en: modificaciones en jurisprudencia, aparición de nuevas técnicas de identificación genéticas y reconocimiento de restos óseos, creación de terapias psicológicas en el tratamiento de traumas producto de la apropiación de identidades; como así también en reflexiones en torno a los conceptos involucrados en el tema de la identidad. ${ }^{2}$ Cabe mencionar al respecto, que estas investigaciones estuvieron acompañadas, sobre todo, a partir de la década de los ochentas de distintas manifestaciones culturales entre las que sobresalen realizaciones cinematográficas llevadas a cabo por familiares e hijos de desaparecidos. Muchos de estos filmes se propusieron indagar, entre otras cuestiones, los límites éticos de la representación y los problemas relativos a la posibilidad de reconstrucción de memorias personales y colectivas. A estos proyectos se sumaron otros, generados fundamentalmente con el propósito de que se constituyeran en medios eficaces para concientizar a la población a favor de una política de recuperación de los jóvenes apropiados. ${ }^{3}$ Entre los títulos y realizadores se destacan las producciones de un puñado de cineastas que, desde su condición de hijas o hijos, compusieron relatos fílmicos en nombre de la memoria de un padre, una madre, ambos, o bien de la propia memoria desgarrada por la violencia del Estado. ${ }^{4}$ En esos casos, como es de esperarse, la reconstrucción de la memoria suscitó diversos tratamientos fílmicos.

Nos encontramos, así, con aquellos que intentaron reflejar historias cotidianas impregnadas de un tono emotivo en torno a la figura del desaparecido. En esos filmes se privilegió el recurso a reproducir, con el menor artificio posible, reportajes íntimos a amigos y familiares cuya intención última era contribuir al conocimiento personal del desaparecido. Un dato revelador de este tipo de cine, es que los testimonios de los pertenecientes a la generación de los padres casi nunca confrontan con las opiniones de hijos. En otras palabras, el hijo(a) en su papel de director(a) no juzga el accionar de los padres, sino que se limita a reproducir, de la manera más adecuada, los relatos acerca de los mismos. De esto resulta que en ocasiones los progenitores aparezcan retratados tanto como víctimas inocentes o como héroes que aceptan su destino y que se encuentran superados por la violencia y la imprevisibilidad

${ }^{2}$ Idem.

${ }^{3} C f$. E. Padilla, "La contribución de los relatos en la interpretación de las identidades", en Carlos Oliva Mendoza, comp., Hermenéutica, subjetividad y política. México, UNAM, 2009.

${ }^{4}$ Cf. A. Amado, La imagen justa. Cine argentino y política (1980-2007). Buenos Aires, Ediciones Colihue, 2009, p.170. 
de las circunstancias de su tiempo histórico. Tal el caso de Nietos, identidad y memoria (2004) de Benjamín Ávila. En tanto, otras realizaciones, entre las que se inscribe Los rubios (2003) de Albertina Carri, se ocuparon de mostrar, además de la imposibilidad de reconstruir la identidad de los padres a través de la memoria propia y la de los otros, el cuestionamiento de los idearios políticos que condujeron a los progenitores a elegir la lucha armada en lugar de la seguridad de la familia y la crianza de los hijos. Una buena muestra en Los rubios de este conflicto es el monólogo que lleva adelante la protagonista, ${ }^{5}$ en el que interpela a la madre ausente acerca de los motivos de su elección, de su decisión final de abandonarla. La escena finaliza con la cámara (llevada por la misma Carri) girando frenéticamente alrededor de la protagonista a quien sólo le queda, como forma extrema de expresión del dolor y de la irreversibilidad de la ausencia, proferir un grito interminable.

Otro tipo de producción, no menos valiosa, que se suma a las anteriores, es aquella que se caracterizó por dar testimonio (en el momento de la realización del film) del estado de la investigación judicial en torno a alguna desaparición con el propósito, incluso, de aproximar nuevas líneas de indagación para el esclarecimiento del caso. Un buen ejemplo de ello es el film de Carlos Echeverría, Juan, como si nada hubiese sucedido (1987). Cabe señalar que al mérito ya otorgado a este film, por ser uno de los pioneros en el tratamiento del fenómeno del desaparecido con auténtico compromiso ético, se le agrega la originalidad de su montaje, que ha sido tomado como modelo por muchos realizadores posteriores. La forma de representación elegida tiene todos los rasgos de un híbrido entre documental y ficción. Este híbrido consiste en el registro minucioso de la investigación llevada a cabo por un periodista (alter ego de Echeverría) sobre la desaparición del estudiante Juan Herman, único desaparecido que se registra en la ciudad de Bariloche. El periodista/actor seguido por la cámara de Echeverría lleva a cabo la tarea, no exenta de riesgos para su vida y la de sus colaboradores, ${ }^{6}$ de entrevistar en forma no complaciente a distintos representantes de la sociedad barilochense (cámara de comercio,

${ }^{5}$ Recordemos que en el film Los rubios, Albertina Carri, la directora, es representada por la actriz Analía Couceyro y que en muchas escenas aparecen ambas.

${ }^{6}$ El 15 de diciembre de 1983, a cinco días de asumir como presidente, Alfonsín sancionó los decretos 157 y 158 . Por el primero se ordenaba a enjuiciar a los dirigentes de las organizaciones guerrilleras ERP y Montoneros; por el segundo se ordenaba procesar a las tres juntas militares que dirigieron el país desde el golpe militar del 24 de marzo de 1976 hasta las Guerras de las Malvinas. El mismo día creó una Comisión Nacional sobre la Desaparición de Personas (Conadep), integrada por personalidades independientes para relevar, documentar y registrar casos y pruebas de violaciones de derechos humanos, y fundar así el juicio a las juntas militares. Así, en 1985 durante su gobierno se inicia el juicio a las Juntas. La importancia que merece el film de Echeverría es que, apenas pasados dos años de estos cruciales acontecimientos, la hace pública. 
intendente, medios de difusión) y, sobre todo, a la cúpula castrense todavía en ejercicio del mando que gobernó la región cuando se produjo la desaparición de Juan Herman. La cámara del director se detiene en los rostros de los militares entrevistados, intentando capturar contradicciones entre la gestualidad manifiesta y la palabra comunicada. Incluso, las imágenes obtenidas logran trasmitir la violencia contenida por la presencia del periodista que no se conforma con escuchar pasivamente un discurso armado sino que se atreve a preguntar y a pedir explicaciones sobre el grado de complicidad de las fuerzas militares en la desaparición de personas.

En suma, lo inédito de Echeverría fue visibilizar (aunque sea por un instante) en el ida y vuelta de preguntas y re-preguntas algo del orden de lo nunca reconocido, lo no dicho que se escapa del control consciente del discurso por parte de los interrogados. Esta modalidad de reportaje iba a contracorriente de la tarea periodística llevada a cabo por esos años, salvo honrosas excepciones. En efecto, en las entrevistas realizadas a los principales jefes militares era habitual que los medios se mostraran condescendientes y la tarea profesional de los periodistas se reducía a escucharlos sin realizar crítica alguna. De ahí la relevancia y osadía que significó la película de Echeverría.

\section{La especificidad inquietante de $M$}

En este camino podemos inscribir otro film, $M$ de Nicolás Prividera (2004). La elección de este film obedece a que en él se advierten elementos que recuperan planteamientos de los filmes anteriores en una síntesis no resuelta. Por un lado, aparece el tema de lo emocional, muy próximo al modo de Nietos, como forma de aproximación empática a la experiencia traumática de desaparición, en este caso de la madre, Martha Sierra; por otro, indaga el eterno conflicto de los límites entre lo público y lo privado. En este caso puntual la cuestión se centra en quién o a quiénes debe hacerse responsable por el esclarecimiento de las desapariciones: ¿es tarea de los familiares o es exclusiva del Estado? En el discurso fílmico también se identifica, como en Los rubios, el pedido de explicación o mejor dicho la recriminación por parte del hijo/director de las elecciones ideológicas que realizó la madre y que la condujeron a su desaparición. Un dato interesante que no se puede soslayar, por sus consecuencias en la formulación discursiva del film, es la influencia que ejercen en el director las distintas hipótesis formuladas sobre los motivos de la detención y posterior desaparición de su madre. La relevancia de éstas radica en que cuestionan las imágenes que el hijo se ha hecho de su progenitora. En efecto, recordemos que para algunos la madre de Prividera fue una auténtica heroína, mientras que para otros fue una "pobre perejil" que tuvo la mala suerte de estar en el momento y 
en el lugar equivocados. Ante esto, cabe preguntarse, qué madre es la que desea el hijo reconstruir en su registro fílmico: la heroína malograda pero responsable de sus actos, o bien la víctima ignorante de las consecuencias de los mismos; pero acaso, ¿se puede elegir entre ambas? En otro orden de cosas, cabe mencionar que a raíz de esta cuestión se dio una áspera controversia, recogida en los medios especializados, entre Albertina Carri -directora de Los rubios- y Prividera. La discusión entre ambos directores derivó en la pertinencia o no de establecer algo así como categorías entre los detenidos-desaparecidos, y en caso de que así fuera, evaluar si las mismas contribuirían al esclarecimiento de los hechos. Acordamos en este punto que cualquier reclamo de justicia sobre detenidos-desaparecidos está reñido por anti-ético con establecer algún tipo de jerarquías entre ellos, discriminando, por ejemplo, entre los más o menos importantes o los más o menos involucrados. Ahora bien, el origen de la controversia se debe -entre otras cosas- a que en la película de Carri se muestra claramente el reconocimiento del papel desempeñado por sus padres en la lucha armada. Se trataba de una pareja de intelectuales muy nombrados en el ambiente cultural de la época y plenamente conscientes de las acciones en las que participaban. En cambio, en $M$ la cuestión gira en torno a las dudas sobre cuál fue el nivel de participación y decisión conscientes de Martha Sierra en la lucha. De ahí la posibilidad de considerar que fuera alguien, al margen de los acontecimientos de la época, detenido trágicamente por error.

En otro plano de análisis, el film también encara el proyecto de reanudar la investigación, al igual que en el de Echeverría, sobre la desaparición de Martha Sierra con la esperanza de que ésta culmine con la condena de los responsables del delito. Este objetivo se materializa en el papel que asume Prividera dentro del film cuando entrevista a los empleados de la Conadep y allegados de su madre. No se conforma con las respuestas dadas y procura, todo el tiempo, cuestionar las razones expuestas. Incluso en una escena, junto a su hermano cuyo protagonismo se reduce a escucharlo en distintas tomas de la película, se enoja ante la negativa de una amiga de su madre a responder preguntas, ya que su médico le ha sugerido no someterse a situaciones estresantes (la mujer padece cáncer de mama). El reproche de Prividera se resume en la siguiente posición: cómo un problema personal, por más grave que éste sea, puede eximirnos de nuestras obligaciones como ciudadanos, más aún en casos en que el testimonio contribuye a esclarecer delitos de lesa humanidad. Aquí se manifiesta nuevamente el conflicto entre lo privado y lo público. En otras palabras, hasta qué punto es ético exigir a alguien que esté dispuesto a rememorar momentos penosos de su vida en contra de su propia voluntad, aun cuando la finalidad sea el logro de un bien público.

Entre todos estos aspectos, que nos permiten poner en comparación y en confrontación a $M$ con los filmes mencionados, hay uno que quiero poner de 
relieve y que lo aproxima a los problemas de la representación de la identidad a partir de los testimonios de memorias fragmentadas, al modo de Los rubios. Viene bien para el caso recordar primero una escena de este último film, aquella en que la protagonista, alter ego de la directora, afirma que la mejor forma de hacer presentes a los ausentes es dejarlos ausentes, pues nunca sabremos quiénes fueron. ${ }^{7}$ En la realización de Prividera, en cambio, la ausencia se transforma en una presencia omnipresente a través de la inclusión, dentro del film, de una película familiar realizada en una cámara súper-ocho. La utilización de ese material como ilustración de una vida, la de Martha Sierra, crea un efecto inquietante y difícil de dimensionar y que no encontramos en los otros filmes mencionados. Si bien reconocemos que en ellos también se utiliza el recurso de los testimonios fotográficos familiares para dar cuenta de los ausentes. El registro fílmico familiar incrustado dentro de la trama de $M$ nos pone en situación de enfrentarnos al rostro del otro, al de Martha. Allí no aparece inmóvil ni de un tono amarillento, al modo de las viejas fotografías, sino viva en un presente eterno, ignorante de ese futuro que nosotros, espectadores, conocemos. Es como si a través de los medios tecnológicos hubiésemos logrado capturar una traza de la vida de Martha, la cual aparece una y otra vez ignorante de su destino y del uso futuro de esas imágenes que le pertenecen. Creo que aquí reside la principal originalidad de la película de Prividera en relación con las otras y que no se cierra en el extrañamiento que provocan esas imágenes de Martha, sino que abre (intencionadamente o no) toda una serie de planteamientos en torno al uso ético y cognitivo de este recurso. Y es que como espectadores de esas imágenes no podemos permanecer indiferentes sin cuestionarnos sobre los límites éticos de utilización de registros fílmicos que toman, de pronto, carácter público bajo distintas formas estetizantes. Antes de evaluar los derroteros de esa singularidad, me referiré a algunos aspectos del film no dichos hasta ahora.

Como mencioné más arriba, el antecedente inmediato de $M$ es el film de Echeverría. No obstante, una diferencia notable es que en este caso la investigación es emprendida por el hijo (el mismo Prividera) cuya madre Sierra desapareció en 1976, cuando él tenía seis años. El desarrollo del film sigue la estructura del policial negro. El director se pone en la piel del presunto detective que asume la investigación y, desde su subjetividad, indaga, se detiene en el detalle, señala y juzga con la intención de responder a cuestiones tales como: ¿cuáles fueron los motivos de la desaparición?, ¿quiénes la conocieron?, ¿quiénes la entregaron o delataron?; preguntas que remiten a un interrogante fundamental: la identidad de Martha Sierra.

${ }^{7} C f$. E. Padilla, "La contribución de los relatos en la interpretación de las identidades", en op. cit., p. 247. 
Si iniciamos nuestro análisis a partir de la gráfica elegida en el título del film, observamos que la misma es elocuente por su simplicidad, ya que en los posters de presentación es indicado mediante una pieza verde cúbica en cuyo centro -en negro- está inscripta la letra M. Sospechamos que se trata de una pieza de algún tipo de juego, quizás un rompecabezas, o mejor dicho, un scrabble. Es decir, desde la presentación del título, el director nos anuncia las dificultades que encontraremos al intentar reconstruir la identidad de su madre desaparecida. Por un lado, la pieza con la $\mathbf{M}$ inscrita en su centro remite a un juego y, por tanto, a seguir ciertas reglas que nos conducirán a alguna palabra posible, pero, por otro, la presencia de esta única pieza niega la posibilidad misma del juego. El ejercicio imaginativo que nos propone esta pieza parece radicar en la búsqueda de las faltantes que nos permitirían armar la palabra adecuada (¿la única?) cuya inicial es M. Pero ¿por qué M? Interrogado el director, afirma que $M$ alude a todo un espectro de palabras cuyas significaciones nos remitirían a la identidad de una persona. En un principio, podríamos pensar que $\mathrm{M}$ alude a "madre", es decir, a la filiación biológica e institucional que la vincula al director del film y, por otra, al del nombre que la identificaba: Martha.

Pero éstas no son las dos únicas soluciones al enigma; a ellas podríamos agregar con la misma legitimidad otras, como por ejemplo: "militancia", "montonero", "memoria", "muerte", "monstruosidad", cuestiones clave sobre las cuales transita conceptualmente el film. Otra consideración, no menor, de las razones de la elección del título del film es que el mismo es un homenaje a un film muy admirado por Prividera: $M$ de Fritz Lang, del año 1931. ¿Qué significa M en el contexto del film de Lang? Según testimonios históricos, remite a "mörder" (asesino, en alemán), cuya inicial es escrita en la espalda del protagonista del film con el propósito de identificarlo y, por ende, perseguirlo para detenerlo. Ahora bien, la temática por la cual es valorado hasta el día de hoy el film de Lang es que exhibe en su trama la posibilidad de que cualquiera de los miembros de una sociedad oculte a un cruel asesino. En efecto, Lang muestra que no hay rasgos perceptibles que nos permitan identificar la monstruosidad. ${ }^{8}$ La originalidad del film reside en la vigencia de la crítica corrosiva que realiza ${ }^{9}$ a toda una sociedad que por ignorancia, indiferencia o complicidad prefiere mirar hacia un costado y no responsabilizarse del lado

${ }^{8}$ Recordemos que el otro título por el cual se conoció la obra y que nos conduciría a clasificarla equivocadamente dentro del género de horror fantástico es "El vampiro negro" o "El vampiro de Dusseldorf".

${ }_{9}^{9}$ El film de Lang se realiza en 1930 antes de la entronización del nazismo en el poder, en una sociedad en la cual ya se vislumbraba una atmósfera de desintegración y desesperación económica. 
siniestro que ella misma está gestando. ${ }^{10}$ Prividera comparte con Lang la tesis de que lo injusto, en sus distintas formas, puede acontecer, pues cuenta -en principio- con la complicidad de toda la sociedad. En ese sentido, su ópera prima procura constituir una expresión de demanda a la responsabilidad colectiva por lo que sucedió durante el proceso. Reclamo que se extiende tanto a las autoridades como a las instituciones y hasta a los mismos compañeros de trabajo y militancia de Martha Sierra, que con su silencio e indiferencia consintieron voluntaria o involuntariamente con lo ocurrido; en suma, el reclamo es a todos los que sabían y callaron. Ahora bien, considerar el problema de la responsabilidad colectiva en la irrupción de procesos históricos nos conduce a preguntarnos acerca de si es posible establecer claramente grados de participación y complicidad en lo acontecido entre los distintos miembros de la sociedad, para proceder al tratamiento jurídico distintivo de los casos. Sabemos que hasta ahora es un punto de difícil resolución ética y política para cualquier sociedad, pues la responsabilidad tiene sentido de ser reclamada en ciertas condiciones, por ejemplo, en relación con una voluntad libre conocedora, al menos, de algunas de las consecuencias de sus actos.

Pero entonces, ¿cómo tratar aquellos casos en donde esas condiciones se dan en forma dudosa? Otro tipo de responsabilidad reclamada por el film de Prividera es la que dirige a los actuales gobiernos democráticos, a los que exige tomar como cuestión de Estado el esclarecimiento de los casos de desaparición durante la dictadura. En ese sentido, el director se niega a aceptar que la búsqueda de indicios en relación con la desaparición de su madre (pasados ya los treinta años) sea sólo asunto de interés privado, una cuestión de consanguinidad que sólo le concierne al círculo familiar íntimo. Aquí, la película transmite un profundo sentimiento de indignación y de enojo en muchas de sus imágenes y monólogos que Prividera realiza ante cámara. Es más, al inicio de $M$, una periodista que entrevista a Nicolás le pregunta abiertamente si está enojado por la situación que atravesó su vida. Él responde que más que enojado tiene bronca, luego se rectifica y acota: "en realidad todos deberíamos tener bronca, porque la desaparición de mi madre no es algo que sólo me pasó a mí y a mi familia sino que nos pasó a todos". Vale acotar en este sentido, que en los extras del material fílmico que acompañan a la presentación de la película, Nicolás recuerda ese reportaje y nuevamente se rectifica, aclarando que cuando dijo que tenía bronca mejor hubiese sido referirse a estar indignado, ya que la indignación no es un sentimiento cualquiera sino una afección generada por un acto ofensivo o injusto. En efecto, lo injusto, al ser reconocido como tal y en vista a ser enmendado,

${ }^{10}$ Otro dato ilustrativo es que el título original previsto por Lang para su film es, y luego fue cambiado, "El asesino está entre nosotros". 
requiere para su resolución de un tratamiento de lo universal y no de lo particular.

\section{La puesta en escena de una incógnita: más allá de un rompecabezas}

Como ya señalamos, la estructura de $M$ se ciñe a ciertos parámetros de una investigación bajo el formato del género policial. Está dividida formalmente en cuatro partes anunciadas con un título, como si se tratara de folios de un expediente policial o judicial, con oraciones que resumen el contenido de lo que vendrá a nivel de representación fílmica. Éstas son: el fin de los principios, los restos de la historia, el retorno de lo reprimido y epílogos. Adoptando el lugar del detective, Prividera nos invita, en nuestro carácter de espectadores, a seguirlo junto a la cámara transformándonos en testigos mudos de sus fracasos en la búsqueda de datos en relación con la desaparición de su madre. En el discurso fílmico se muestra de continuo el conflicto acerca de quiénes son los responsables de llevar adelante la investigación. ${ }^{11}$ En consonancia con ello, en el plano formal, el film se organiza desde la primera persona, pero sin la voz en off naturalmente asociada a ella. Consideramos que esto se debe a que el director se ha propuesto no cerrar la mirada sobre el asunto a su propio punto de vista, de ahí que haya optado en aparecer como un personaje más (si bien él es el que hace avanzar y orientar la acción) con el propósito de que el espectador saque sus propias conclusiones. En el comienzo, lo acompañamos por los laberintos burocráticos de los organismos del Estado, como los de Derechos Humanos, compartiendo junto a él el desconcierto y la frustración ante la palpable evidencia de que mucha de la información recopilada en esas oficinas se ha perdido y la que aún subsiste no se encuentra sistematizada, actualizada o siquiera centralizada. Ante esto, se presiente una resignación generalizada, que en boca de los empleados se resume en la frase: "Qué le vamos a hacer, la cosa es así. ¿Que tenga suerte!" En ese punto, el enojo del investigador se hace manifiesto y la película lo trasmite eficazmente, sin evitar la incomodidad que pudiera despertar en el espectador verse llevado involuntariamente a acompañarlo en semejante muestra de franqueza. ${ }^{12}$

Luego, la búsqueda continúa a través de la recolección de los testimonios de los amigos y compañeros de su madre mediante la técnica del reportaje, que

${ }^{11}$ No olvidemos que el Estado bajo el régimen de dictadura fue el que accionó contra ciudadanos haciéndolos desaparecer.

${ }^{12}$ Las irónicas manifestaciones de Prividera que aparecen en el film acerca de la falta de actualización de datos del libro Nunca más en sus distintas ediciones le deparó fuertes comentarios de críticos de cine comprometidos con la defensa de los derechos humanos, como por ejemplo Gustavo Noriega, director de la revista El Amante del Cine. 
lleva adelante personalmente. Aquí se da la particularidad de que muchas de las personas a las que entrevista lo conocieron de niño, pues era habitual que Nicolás acompañara a su madre a su lugar de trabajo. ${ }^{13}$ Creemos que por esta razón los reportajes se desenvuelven en cierta atmósfera de tensión contenida, ya que las preguntas que realiza Prividera adulto provocan naturalmente cierta incomodidad en los entrevistados, pues el interrogatorio al que los somete, aunque amable en las formas, constituye en última instancia un pedido de explicaciones. La imagen que resulta de las distintas voces que hablan sobre Martha como profesional, trabajadora, compañera, militante, amiga, madre, es algo semejante a los intentos vanos de reconstruir las figuras de un mosaico roto, al que le faltan demasiadas piezas para tener una visión de conjunto, y que al mismo tiempo (paradójicamente) le sobran otras que no encajan en ninguna parte. Cabe preguntarse si el recurso heurístico del rompecabezas, o el modo en que los arqueólogos reconstruyen piezas del pasado encontradas en una excavación, puede echar luz sobre el problema de la identidad que estamos tratando. Bauman sostiene que para teorizar sobre cuestiones de identidad, la alegoría del rompecabezas sólo es esclarecedora a medias; ya que hay muchas piezas sobre la mesa que uno espera colocar en un conjunto medianamente coherente, pero la imagen que debería aparecer al final no nos es proporcionada de antemano, por lo cual no se puede estar seguro de tener todas las piezas necesarias para componerla. ${ }^{14}$

Podemos decir que resolver un rompecabezas persigue una meta. En el caso de la identidad, en cambio, toda la labor persigue unos medios, ya que no se comienza por la imagen final sino por un número de piezas que se han obtenido o que merece la pena tener, y luego se intenta averiguar cómo se pueden ordenar o reordenar para conseguir algunos (¿cuántos?) dibujos satisfactorios. ${ }^{15}$

Por tanto, podríamos decir que no hay consuelo seguro a nuestra disposición cuando se elabora lo que será la identidad de una persona desaparecida, $o$ de cualquier otra, ya que al problema, respecto a la pertinencia o no del modelo

${ }^{13}$ En aquellos años en el Instituto Nacional Tecnológico Agropecuario (INTA) sede Castelar existía una guardería y jardín de infantes a la que asistían los hijos de los trabajadores que pertenecían a distintos estamentos del Instituto (profesionales, obreros, personal de maestranza) y los hijos de los vecinos del barrio. Precisamente esa escuelita había sido un logro de la preocupación social de las asociaciones políticas y sindicales que funcionaban dentro del INTA y de las que participaba Martha Sierra.

${ }^{14} C f$. Z. Bauman, Identidad. Trad. de Daniel Sarasola. Buenos Aires, Losada, 2005, p. 105.

${ }^{15}$ Ibid., p. 107. 
del rompecabezas para tratar cuestiones de este tipo, se agrega el que las piezas encontradas tampoco son de significación estable. En efecto, están sujetas a los vaivenes de la memoria, del olvido y de las continuas re-contextualizaciones del pasado, resultado esto último de los aportes nuevos que se introducen de continuo en el relato a través de la intervención de distintos actores, o de los mismos en diferentes circunstancias políticas/sociales.

\section{La intensidad de una imagen: ¿cuál?}

Junto a la indagación realizada en el film de Prividera, un fenómeno no menos importante que no podemos dejar de lado son las distintas filmaciones y fotografías de origen caseras que el director intercala en su desarrollo. Sabemos, por boca del director, de la gran afición de Martha y de su padre por esos tipos de registros materiales, preocupación continuada en el presente por el hijo. Estas filmaciones realizadas en la espontaneidad de la vida cotidiana constituyen una película dentro de otra, quizá de visión más incómoda y sobrecogedora que la de Nicolás, pues su objetivo no fue ser vista por ninguno de nosotros, por lo cual el extrañamiento que provoca es mayor. Ahí está Martha Sierra filmada en su intimidad, en todo tipo de escenarios y situaciones: en viajes, en el trabajo, con Nicolás niño en el INTA, en reuniones de militancia, o en la privacidad del hogar. Filmada, ¿por quién? Por compañeros y en especial y, sobre todo, por la mirada enamorada de su esposo. En esas filmaciones caseras Martha no nos mira a nosotros, mira a un otro que ha decidido no aparecer nunca en la película de Nicolás, de ahí que la actuación involuntaria de Martha está dedicada al que la filma, al que la miró originariamente a través de la cámara. Y este hombre, el padre del director, no registrado en $M$ sino sólo en alguna que otra foto borrosa, o mencionado en el testimonio indirecto de parientes, es el director de una película a la que asistimos en calidad de voyeurs accidentales, espiando -con permiso del hijo- la intimidad de esa mujer desaparecida. En esas imágenes que se organizan con gran sentido estético creemos asir algo de la autenticidad de Martha, la cual se muestra en toda su inconsciencia como actriz principal del film de su vida. Al respecto, el modo en que es filmada nos recuerda a las imágenes a las que nos tienen acostumbrados directores de la nouvelle vague francesa, como Chabrol o Godard. En el film de su vida es captada muchas veces pensativa, en gestos no ensayados, ensimismada, con la mirada perdida en el vacío, amamantando a su hijo recién nacido, detrás de un alambrado. Y en otras, como si avizorara su destino de forma premonitoria, la vemos con la mirada fija seducida por el hipnótico fluir del río. Esta imagen produce estupor, pues ese río es el Río de la Plata, en donde los vuelos de la muerte acostumbraban arrojar los cuerpos maniatados, muchas veces con vida 
y sedados. Lugar en donde hoy quizá sus restos descansan. De modo similar, a la afirmación que sostiene que una imagen vale más que mil palabras, podemos decir que esa filmación casera nos aproxima más que mil testimonios a la auténtica humanidad de Martha, al rostro del otro.

Llegados a este punto, creemos que saber, por ejemplo, cuál fue su grado de participación en los movimientos políticos de esos años, es decir, exponer las razones de su captura y luego de su desaparición, es superfluo, casi banal. Con esto no queremos decir que debe darse por finalizada la investigación en torno a su desaparición, sino más bien que no es necesario saber quién fue Martha para continuarla hasta sus últimas consecuencias. Ahora bien, arribamos a esta conclusión a partir de la experiencia que nos provocan esas imágenes capturadas por su marido en una cámara súper-ocho. Ahí, Martha es eterna, pues ha quedado detenida para siempre en su tiempo. En cada fotograma regresa a nuestro tiempo, a treinta años de desaparecida, en forma casi fantasmagórica, revelándonos en cada toma la incógnita en que se sume toda identidad. Ocurre que la Martha filmada, valga la paradoja, es ella y no obstante no es ella, es decir: es la de su esposo, la que él quiso ver; es la que rescata finalmente el hijo ${ }^{16}$ en su film $M$ en su peculiar selección de imágenes y fotografías; es aquella con la que nos quedamos cada uno de nosotros que asistimos a la proyección, pues en nuestro carácter de espectadores volvemos a refigurar de acuerdo a la experiencia de vida propia, la Martha del film de Prividera. Ese fenómeno tiene lugar porque la cámara crea un artificio, pues revela -ante todo- la peculiar perspectiva del que ve a través de ella. Perspectiva, a su vez, que será completada por cada espectador desde su mundo de la vida. Así, Martha, en principio, es la que su esposo decidió eternizar para sí mismo. Ahora bien, ¿qué hay de la película del hijo? Sostenemos que Prividera crea, ex profeso, un artificio del artificio. En este segundo nivel interviene como parte interesada representándose a sí mismo. Es más, en una de las tomas su rostro aparece junto al de su madre. Aquí los recursos que nos provee la tecnología filmica permite realizar lo imposible: que madre e hijo aparezcan juntos y con la misma edad, treinta y seis años. El rostro de Nicolás adulto junto al de su madre, crea la ficción de que ambos comparten el mismo presente, aquel en el que Martha pareciera participar junto a su hijo de la investigación acerca de su propia desaparición.

En otras palabras, la originalidad que logra Prividera con $M$ es explorar acerca de la consecuencias de radicalizar lo ficcional para el esclarecimiento del tema de la identidad. Precisamente, el film es una ficción dentro de otra

${ }^{16}$ Mucho de lo expresado por Prividera en imágenes en torno a su madre desaparecida nos trae reminiscencias de las reflexiones de Barthes en su Diario de duelo, 26 de octubre de 1977-15 de septiembre de 1979. México, Siglo XXI, 2009. 
en donde la segunda, la filmación del padre en súper-ocho, nos conduce a que sea la misma Martha, sin saberlo, la que pone en escena su vida ante nosotros. Asistimos así a la intimidad de una persona a partir de la mirada de quien la amó y podríamos sostener que esa mirada es la que la constituye en su forma más auténtica. Martha, por ende, no es un número de identificación, un nombre, un rostro desdibujado y amarillento, alguien a quien podríamos olvidar fácilmente, sino al contrario, su humanidad presentada bajo este formato nos aproxima en forma plena a la nuestra.

\section{A modo de comentario final}

En los años de la recomposición democrática, iniciados a fines de 1983 con el gobierno de Raúl Alfonsín, las ficciones ensayaron diferentes poéticas para figurar la experiencia de extrema violencia por la que atravesó la sociedad. Las desapariciones, la tortura, el exilio, formaron parte del repertorio fílmico de los primeros años de posdictadura. Carlos Echeverría inscribió formal y temáticamente en su film documental Juan, como si nada hubiera sucedido (1987) la investigación emprendida sobre el secuestro y la desaparición en la ciudad de Bariloche de un estudiante universitario y militante peronista durante la dictadura militar. La narración en primera persona, un actor en representación del realizador, la inscripción narrativa de cada etapa de la investigación emprendida, entre otros recursos visuales y narrativos utilizados en el documental de Echeverría, aportaron un modelo que tuvo una notoria influencia en las obras realizadas posteriormente en ese género.

Por su parte, el procedimiento de Prividera consiste, por un lado, en reemplazar una sustracción con una imagen: incluye innumerables fotografías y filmes caseros en Súper-ocho de la madre, documentos visuales y mudos que atestiguan tanto sobre la singular belleza de Marta Sierra como la del ojo enamorado -e implícito- que registraba en el pasado cada uno de sus movimientos. Además de constituirse en un contundente alegato político social sobre la deuda colectiva que todos debemos contraer con nuestros desaparecidos, $M$ es sobre todo un elocuente ejercicio fílmico de extrañamiento en donde lo real y lo ficcional, lo privado y lo público, el pasado y el presente se confunden, volviéndonos conscientes de la complejidad de los problemas que supone todo intento de esclarecimiento de la identidad como existencia particular histórica.

En este sentido, si Los rubios pone en escena la estupefacción ante una investigación que se ve desmentida una y otra vez por las múltiples voces que no permiten siquiera avizorar una perspectiva de identidad, y donde los recursos del cine exhiben más bien su imposibilidad de representación (o 
la representación es de esa imposibilidad); si Nietos, al contrario, apuesta a sostenerse en la filiación y busca entonces conmovernos desde la elocuencia de los relatos, que nos hablan siempre desde un afecto que sostiene y vincula, anclando así la experiencia en un compromiso que busca ser compartido; $M$ radicaliza la distancia del primero pero para comprometernos en otro sentido que el segundo. No sabremos jamás quién fue Marta, pero ahí está, siempre viva en su presente que nos reclama. 